\title{
Pazopanib Inhibits Tumor Growth, Lymph-node Metastasis and Lymphangiogenesis of an Orthotopic Mouse of Colorectal Cancer
}

\author{
GUANGWEI ZHU ${ }^{1,2,3,4}$, MING ZHAO ${ }^{1}$, QINGHONG HAN ${ }^{1}$, YUYING TAN ${ }^{1}$, YU SUN ${ }^{1,2}$, \\ MICHAEL BOUVET ${ }^{2}$, SHREE RAM SINGH ${ }^{5}$, JIANXIN YE ${ }^{3,4}$ and ROBERT M. HOFFMAN ${ }^{1,2}$ \\ ${ }^{1}$ AntiCancer, Inc., San Diego, CA, U.S.A.; \\ ${ }^{2}$ Department of Surgery, University of California, San Diego, CA, U.S.A.; \\ ${ }^{3}$ Department of Gastrointestinal Surgery 2 Section, \\ The First Hospital Affiliated to Fujian Medical University, Fuzhou, P.R. China; \\ ${ }^{4}$ Key Laboratory of Ministry of Education for Gastrointestinal Cancer, \\ Fujian Medical University, Fuzhou, P.R. China; \\ ${ }^{5}$ Basic Research Laboratory, National Cancer Institute, Frederick, MD, U.S.A.
}

\begin{abstract}
Background/Aim: Pazopanib (PAZ) can inhibit tumor progression, but whether PAZ inhibits lymph node metastasis and lymphangiogenesis in colorectal cancer is still unknown. The aim of the present study was to determine the efficacy of PAZ on tumor growth, lymph node metastasis and lymphangiogenesis in an orthotopic nude mouse model in colorectal cancer. Materials and Methods: CT-26-green fluorescence protein (GFP)expressing mouse colon cancer cells were injected into nude mice to establish a subcutaneous colorectal cancer model and were treated with saline and PAZ. Additionals subcutaneous tumors were harvested and cut into $5 \mathrm{~mm}^{3}$ fragments, then tumor fragments were implanted orthotopically in the cecum to establish an orthotopic colorectal-cancer nude mouse model. Orthotopic mice were randomized into two groups for the treatment with saline and PAZ, respectively. Tumor width, length and mouse body weight was measured twice a week. The Fluor Vivo imaging system was used to image the GFP. Hematoxylin $\&$ eosin staining and immunohistochemical staining was used for histological analysis. Results: PAZ inhibited the growth of
\end{abstract}

This article is freely accessible online.

Correspondence to: Robert M. Hoffman, AntiCancer, Inc, 7917 Ostrow St, San Diego, CA, 92111, U.S.A. Tel: +1 8586542555, email: all@anticancer.com; Jian-Xin Ye, Department of Gastrointestinal Surgery 2 Section, The First Hospital Affiliated to Fujian Medical University, 20th Chazhong Road, Fuzhou, 350005, PR China. Tel: +86 13809553280, e-mail: yejianxinfuyi@126.com; Shree Ram Singh, Basic Research Laboratory, National Cancer Institute, Frederick, MD 21702, U.S.A. Tel: +1 3018467331, e-mail: singhshr@mail.nih.gov

Key Words: Pazopanib, orthotopic tumor, lymph node metastasis, lymphangiogenesis, colorectal cancer, nude mice. subcutaneous colorectal cancer, as wells as orthotopic transplanted colorectal cancer tumors. PAZ suppressed lymph node metastasis and lymphangiogenesis in the orthotopic colon cancer model. No significant changes were observed in the body weight between the control and the mice treated with PAZ. Conclusion: PAZ can inhibit the growth of colorectal cancer and inhibit lymph node metastasis and lymphangiogenesis in orthotopic colon cancer nude mouse models.

Lymph node metastasis is frequently occurrs in colorectal cancer, indicating at least stage III (1-4). Lymphangiogenesis is necessary for lymph node metastasis (5). It has been demonstrated that vascular endothelial growth factor receptors (VEGFRs) play an important role in lymphangiogenesis (6-11). Blocking VEGFR-2/3 can block lymphangiogenesis and lymphatic metastasis of colorectal cancer (12).

Pazopanib (PAZ) is an orally available, multi-targeting tyrosine kinase inhibitor of VEGFRs, including VEGFR-1, VEGFR-2 and VEGFR-3 (13). PAZ is a potent inhibitor of all three VEGF receptors (13). PAZ has been shown to control tumor growth and progression by blocking angiogenesis through targeting of VEGFRs (14). In the present study, we used an orthotopic model of the CT26 mouse tumor to determine the efficacy of PAZ on colorectal cancer growth, lymph node metastasis and lymphangiogenesis.

\section{Materials and Methods}

Cell culture. The CT26-GFP (green fluorescence protein) cell line (murine colon cancer) was from AntiCancer Inc (http:// www.anticancer.com; San Diego, CA, USA). CT26-GFP was cultured in RPMI 1640 (GBICO-BRL, Grand Island, New York, NY, USA), supplemented with $10 \%$ fetal bovine serum (FBS) (BioPioneer Inc. San Diego, CA, USA) at $37^{\circ} \mathrm{C}$ in $5 \% \mathrm{CO}_{2}$ saturated humidity. 
A

\section{Pazopanib}

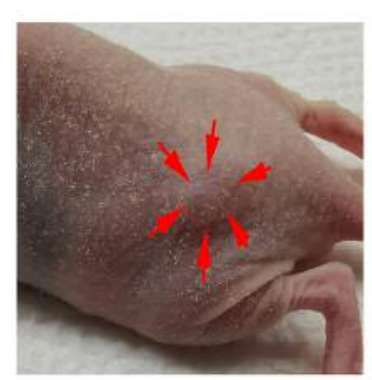

B

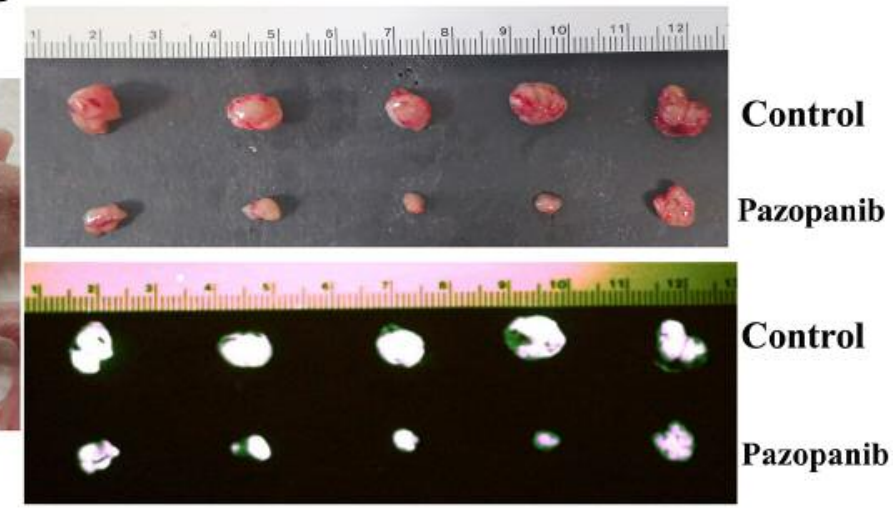

C

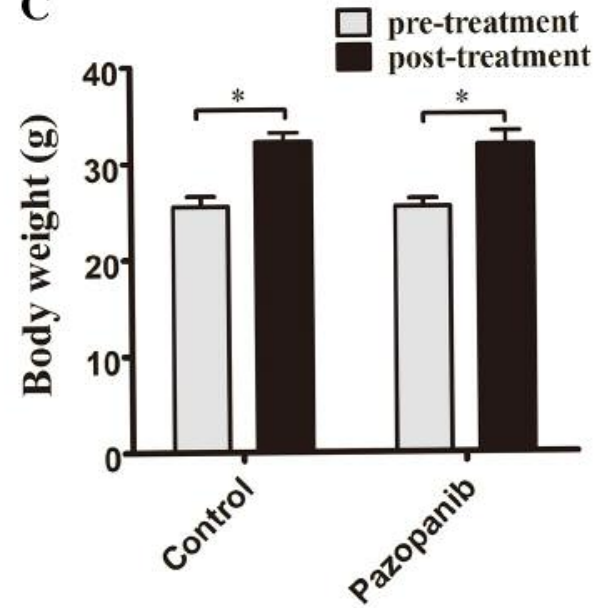

D

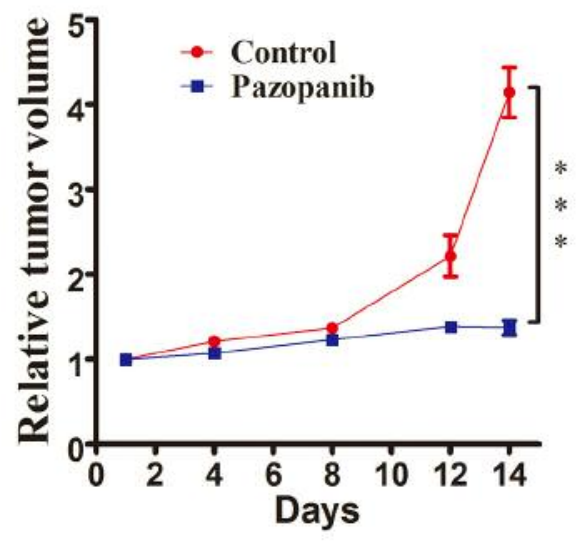

Figure 1. PAZ inhibited the growth of subcutaneously implanted CT26-GFP in nude mice in a model of colorectal cancer. (A) photographs of representative CT26 subcutaneous tumors of colorectal cancer in the PAZ and control groups at treatment day 14. Arrows indicate the margins of the tumors. (B) Photographs (upper panel) and fluorescence images (black and white; lower panel) of subcutaneous tumors from the control and the PAZ groups. (C) Mouse body weight. Bar graphs show mouse body weight in the PAZ and in the control groups at pre-and post-treatment. (D) Line graphs indicate the relative subcutaneous tumor volume (ratio of tumor volume at each time point to volume at the start of the treatment) for the PAZ and the control group. $(N=5, * p<0.05 ; * * * p<0.001)$.

Mice. Athymic nu/nu nude mice (4-6 weeks) were obtained from AntiCancer Inc. Mouse housing, feeding and anesthesia were performed as described in our previous publications $(15,16)$. To minimize any suffering of the animals, anesthesia and analgesics were used for surgical experiments and mice were humanely sacrificed based on methods we have previously published $(16,17)$. All animal studies including surgery and imaging were conducted with an AntiCancer, Inc. Institutional Animal Care and Use Committee (IACUC)-protocol specifically approved for this study including surgery and imaging, and in accordance with the principals and procedures outlined in the National Institute of Health Guide for the Care and Use of Animals under Assurance Number A3873-1 (15).

Establishment of subcutaneous and the orthotopic nude mouse models using CT26-GFP cells. CT26-GFP cells $\left(10^{6}\right)$ were injected into the left thigh of nude mice $(n=10)$. When the tumor volume reached approximately $100 \mathrm{~mm}^{3}$, mice were randomly separated into 2 groups (5 mice/per treatment group): i) Pazopanib-treated
(100 mg/kg, oral gavage, daily for 2 weeks) and ii) control (saline $0.1 \mathrm{ml}$, oral gavage, daily for 2 weeks) groups. Tumor length, width and mouse body weight was measured twice per week. Tumor volume was calculated using the following formula:

Tumor volume $\left(\mathrm{mm}^{3}\right)=$ length $(\mathrm{mm}) \times$ width $(\mathrm{mm}) \times$ width $(\mathrm{mm}) / 2$

Subcutaneous CT26-GFP tumors grown in the nude mice were harvested, cut into $5 \mathrm{~mm}^{3}$ fragments, and implanted as intact tumor tissue orthotopically into new nude mice using the following procedure: i) nude mice were anesthetized using a ketamine-mixed drug, ii) an approximately $1 \mathrm{~cm}$ skin incision was made in the middle of the abdomen, iii) tumor fragments were implanted the cecum, and iv) wounds were closed using 6-0 nylon sutures, as described before (18). After two weeks, tumors were imaged using the FluorVivo imaging system (INDEC Biosystems, Santa Clara, CA, USA) (19). When tumors grew approximately to $100 \mathrm{~mm}^{3}$, mice were randomly separated into 2 groups (5 


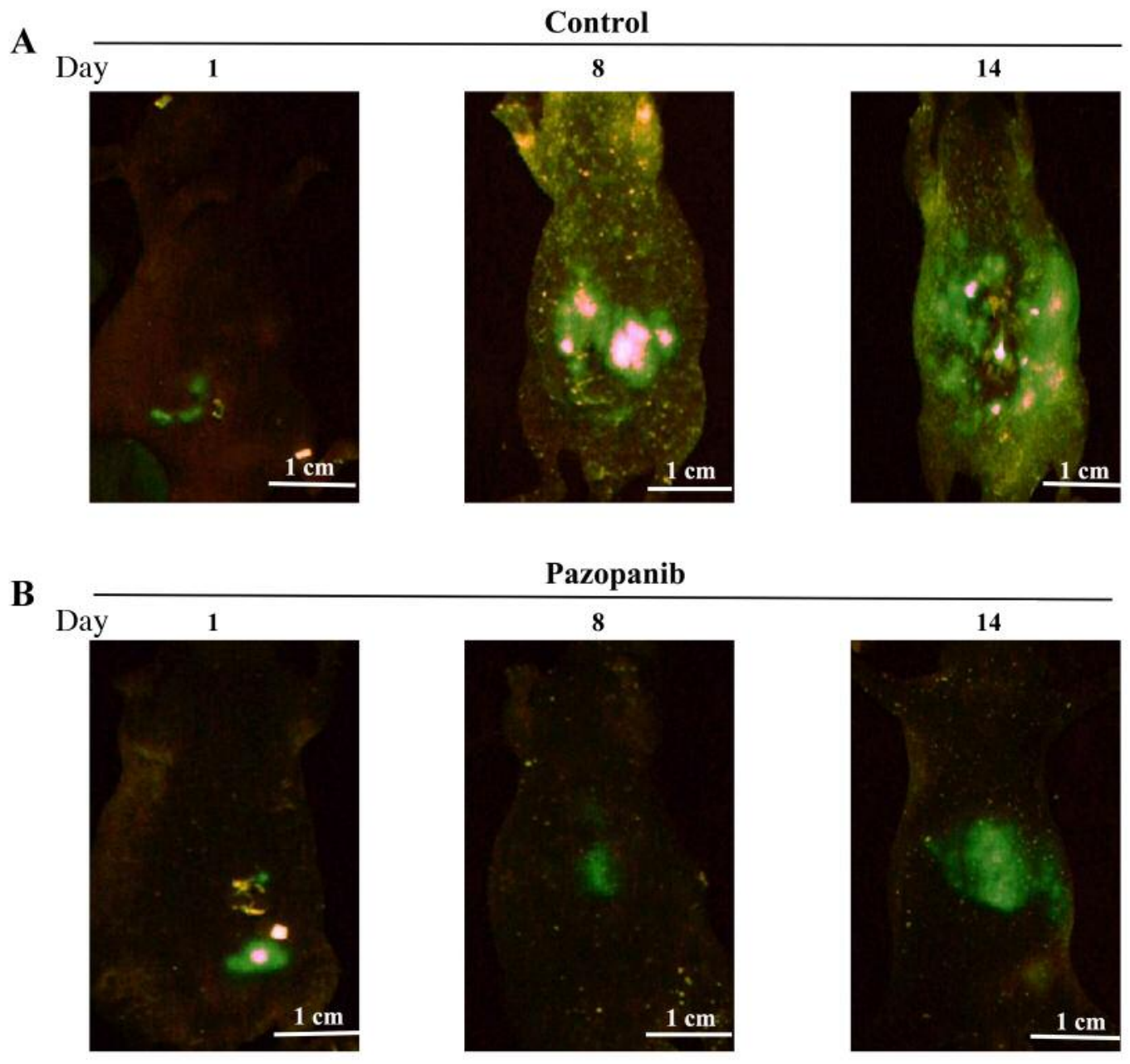

Figure 2. Longitudinal non-invasive in vivo fluorescence imaging of tumor progression over time in nude mice treated with PAZ in the CT26-GFP orthotopic colorectal cancer model. Fluorescence imaging was performed on days: i) 1, ii) 8, and iii) 14 after the initiation of the treatment. (A) Control group $(N=5)$ (B) PAZ group $(N=5)$.

mice/per treatment group): i) Pazopanib-treated (100 mg/kg, oral gavage, daily for 2 weeks) and ii) control (saline $0.1 \mathrm{ml}$, oral gavage, daily for 2 weeks) mice. Tumors were imaged on the $8^{\text {th }}$ and $14^{\text {th }}$ days from the start of the treatment. Mouse body weight was measured twice a week. Data are presented as a mean \pm SD.

Hematoxylin and eosin $(H \& E)$ staining and analysis. Fresh orthotopic tumors and lymph node tissues were fixed in $10 \%$ formalin and embedded in paraffin before sectioning and staining Tissue sections $4 \mu \mathrm{m}$ thick were deparaffinized in xylene and rehydrated in ethanol series. H\&E staining was performed according to standard protocols (19). Image acquisition was performed using a BHS system microscope (Olympus Corporation, Tokyo, Japan) and images were analyzed with INFINITY ANALYZE software (Lumenera Corporation, Ottawa, Canada) (20).

Immunohistochemistry (IHC) and evaluation. Serial sections, 4- $\mu \mathrm{m}-$ thick, were deparaffinized in xylene and rehydrated in ethanol series. The antigen was repaired by heating in sodium citrate $(\mathrm{pH} 6.0)$ and then blocked by a non-specific antigen. Subsequently, $4-\mu \mathrm{m}$-thick
Table I. PAZ inhibits nude mice lymph-node metastasis of orthotopic colorectal cancer tumors.

\begin{tabular}{lcc}
\hline Condition & Control group & Pazopanib \\
\hline Tumor formation & $5 / 5(100 \%)$ & $5 / 5(100 \%)$ \\
liver metastasis & $0 / 5(0)$ & $0 / 5(0)$ \\
lung metastasis & $0 / 5(0)$ & $0 / 5(0)$ \\
Ascites & $4 / 5(80 \%)$ & $1 / 5(20 \%)^{\mathrm{a}}$ \\
Lymph node metastasis & $5 / 5(100 \%)$ & $3 / 5(60 \%)^{\mathrm{a}}$ \\
\hline
\end{tabular}

${ }^{\mathrm{a}} p$-Value $<0.05$.

slices of tumor specimen were incubated with rabbit polyclonal antimouse LYVE-1 antibody (1:400, Abcam, Cambridge, MA, USA) overnight in a humidified box at $4^{\circ} \mathrm{C}$, followed by incubation with a biotinylated goat anti-polyvalent antibody (Abcam, Cambridge, MA, USA). Specimens were then incubated for $10 \mathrm{~min}$ in streptavidin peroxidase, followed by incubation in DAB for 1-8 $\mathrm{min}$ and 
A

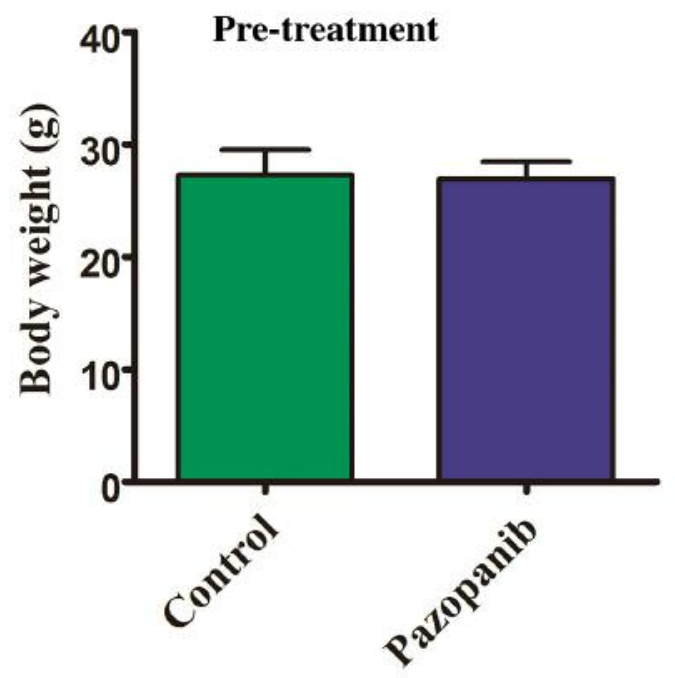

B

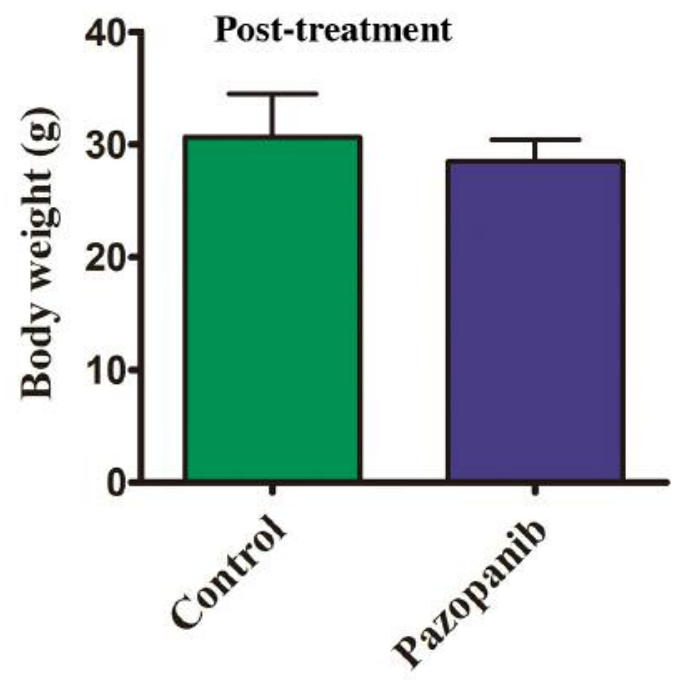

Figure 3. Effect of PAZ on the body weight of CT-26-GFP orthotopic colorectal cancer mouse models. Bar graphs show body weight in the control and the PAZ groups at pre-treatment (A) and 2 weeks post initiation of treatment (B). There were no significant differences between the two groups $(N=5$ in each group, $p>0.05)$.

hematoxylin for $2 \mathrm{~min}$. All steps were performed in accordance with the protocol of the rabbit-specific HRP/DAB (ABC) detection IHC kit (Abcam, Cambridge, MA, USA) at room temperature. Lymphatic vessel density was measured as described in our previous publication (21). Samples were imaged using the BHS system microscope and were analyzed using the INFINITY ANALYZE software.

Statistical analysis. All statistical analyses were performed using the GraphPad Prism 5 software (GraphPad Software, Inc. La Jolla, CA, USA). The paired $t$-test was used for the parametric test to compare the means between two related groups. The data are expressed as a mean \pm SD. A $p$-Value of $<0.05$ was considered statistically significant.

\section{Results}

PAZ inhibited the growth of the CT26-GFP subcutaneous nude mouse colon-cancer model. To initially test the efficacy of PAZ in the CT-26 colorectal cancer we used a subcutaneous mouse model. The tumor volumes at the end of the experiment were: i) PAZ-treated group: $414.4 \pm 66.2 \mathrm{~mm}^{3}$, and ii) control group: $137 \pm 19.1 \mathrm{~mm}^{3}$ (Figure 1A). Photographs and fluorescence images of the control subcutaneous tumors and PAZ-treated group are shown in Figure 1B. The control group tumor grew more than 4 times lager after 2 weeks compared to the time of the initial treatment (tumor-volume ratio $=4.15 \pm 1.05$ ). The PAZtreated group inhibited tumor growth (tumor-volume ratio $=1.38 \pm 0.19, p<0.001$ ) compared to the control (Figure 1D). Two weeks following treatment, mouse body weight was greater compared to the pre-treatment weight in both groups (Control group average weight: $25.6 \mathrm{~g} v s .32 .2 \mathrm{~g}, p<0.05$; PAZ group average weight: $25.5 \mathrm{~g} \mathrm{vs.} 31.9 \mathrm{~g}, p<0.05$ ) (Figure 1C).
PAZ inhibited the growth and metastasis of the orthotopic CT26-GFP colon-cancer nude mouse model visualized by GFP imaging. The GFP images the FluorVivo System in mice treated with PAZ or saline (Figure $2 \mathrm{~A}$ and B; left panel). Following treatment for 8 days, green fluorescence in the control group was significantly higher compared to that of the PAZ group (Figure 2A and B; middle panel). Following 14 days of treatment, the green fluorescence in the control group was wide spread, occupying the entire abdominal area (Figure 2A; right panel); however, green fluorescence in the upper abdomen of the PAZ-treated group was less compared to the control group (Figure 2B; right panel).

Body weight of mice with orthotopic colorectal-cancer tumors. There was no significant difference observed in body weight between the two groups (control group vs. PAZ group) (Figure $3 \mathrm{~A}$ and $\mathrm{B})$.

PAZ inhibited lymph node metastasis in the orthotopic CT26GFP colorectal cancer model. In the control group, the number of lymph node metastases was higher compared to the PAZ group (Figure 4C and F). Figures $4 \mathrm{~A}-\mathrm{C}$ and D-F show the control group and the PAZ group, respectively, where the metastatic status was visualized as also shown in Table I. Both groups of nude mice were under orthotopically transplantated into the cecum with colon cancer $100 \%$ success. We found in the control group that $80 \%$ of nude mice had ascites formation, while only $20 \%$ of the PAZ group had ascites (Figure 4A and D). No liver or lung metastasis was found in either group. 
A

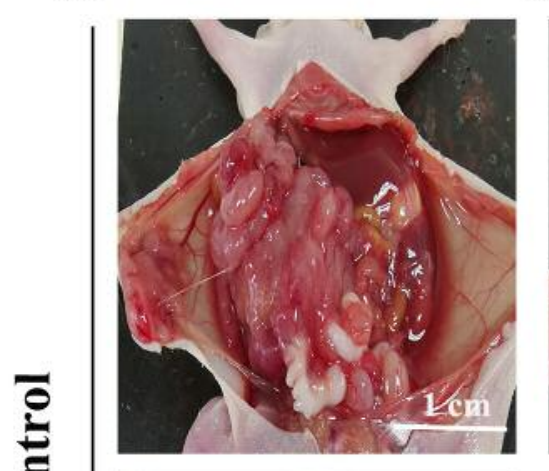

B
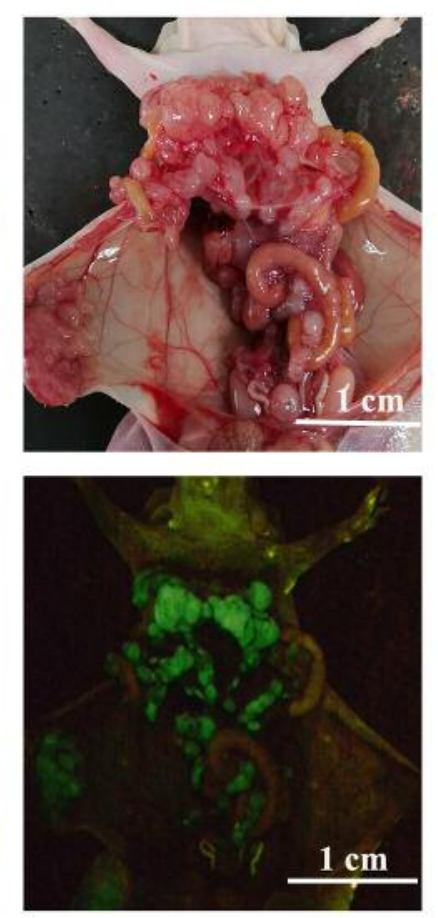

$\mathbf{E}$
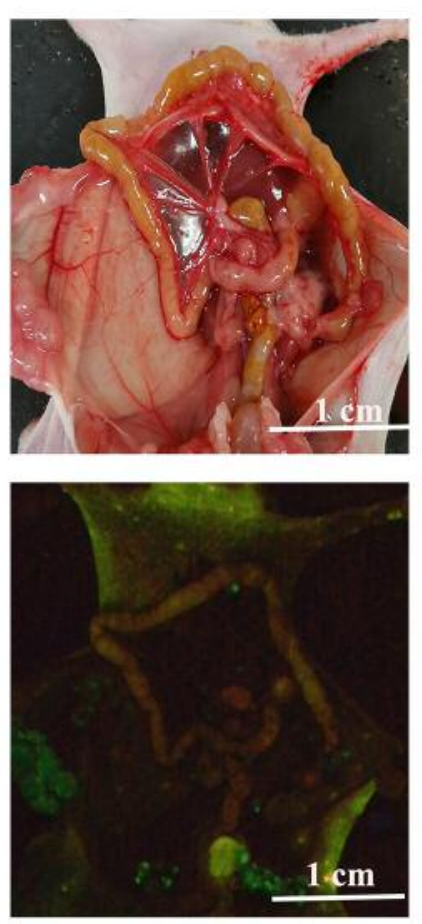

C
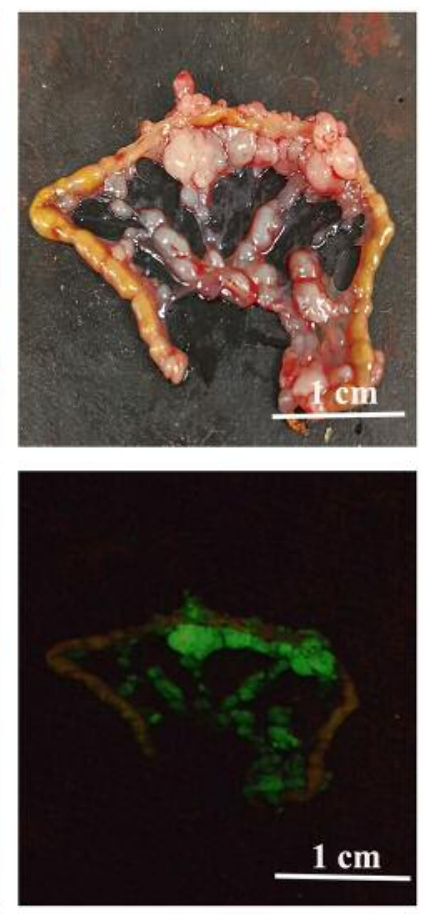

F
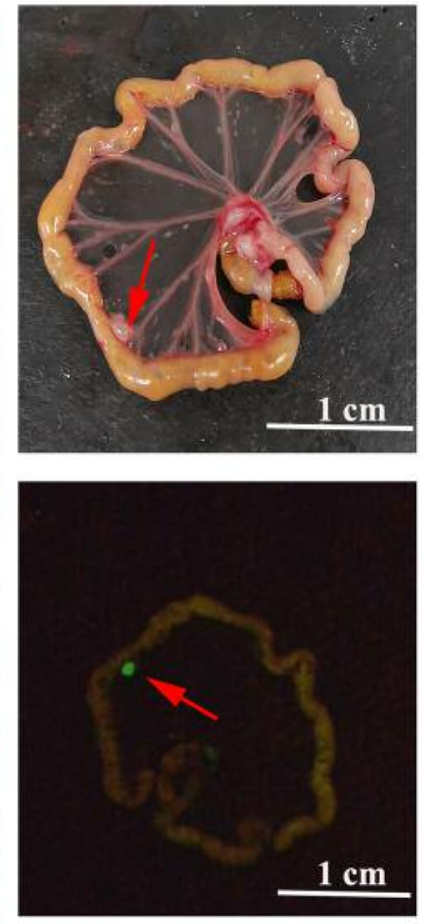

Figure 4. Photographs and fluorescence images of orthotopic CT-26-GFP colorectal cancer nude-mouse model at autopsy in the control and PAZ groups. (A-C) Representative photographs of the control group (upper panels) and corresponding fluorescence images (lower panels). (A) Nude mice have bloody ascites, and tumors show GFP fluorescence. (B) After removal of the transplanted tumor, many metastatic lymph nodes can be seen, particularly in the mesentery $(C)$. (D-F) Representative photographs of the PAZ group (upper panels) and corresponding GFP images (lower panels). (D) Nude mice do not show bloody ascites in the PAZ group. (E) Following removal of the transplanted tumor, images show metastatic lymph nodes expressing GFP, with very few metastatic lymph nodes in the isolated mesentery (arrows in F). 
A

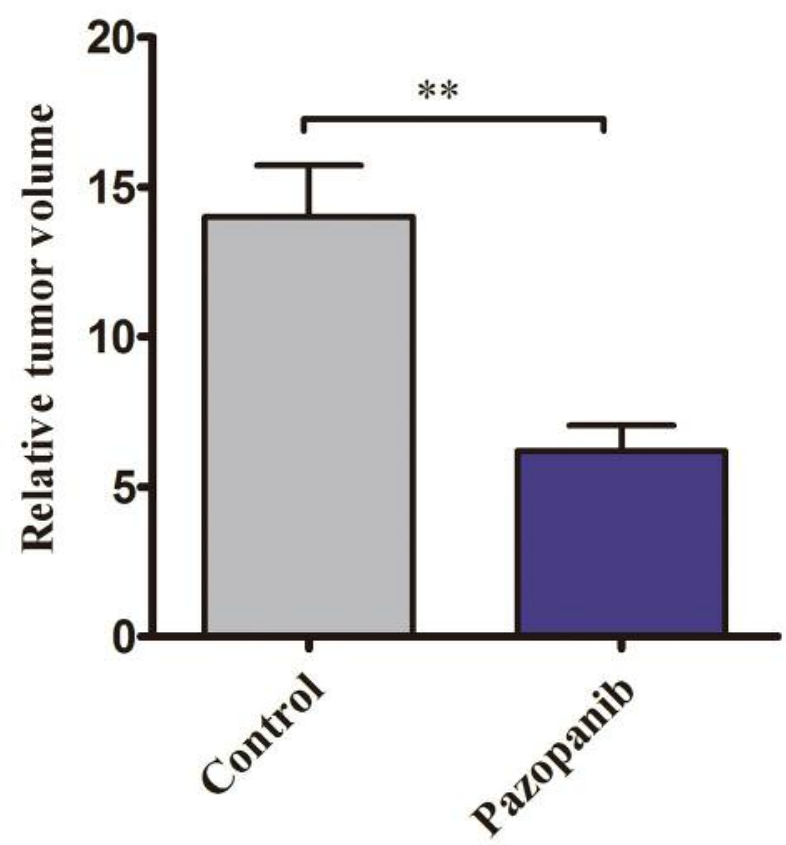

B

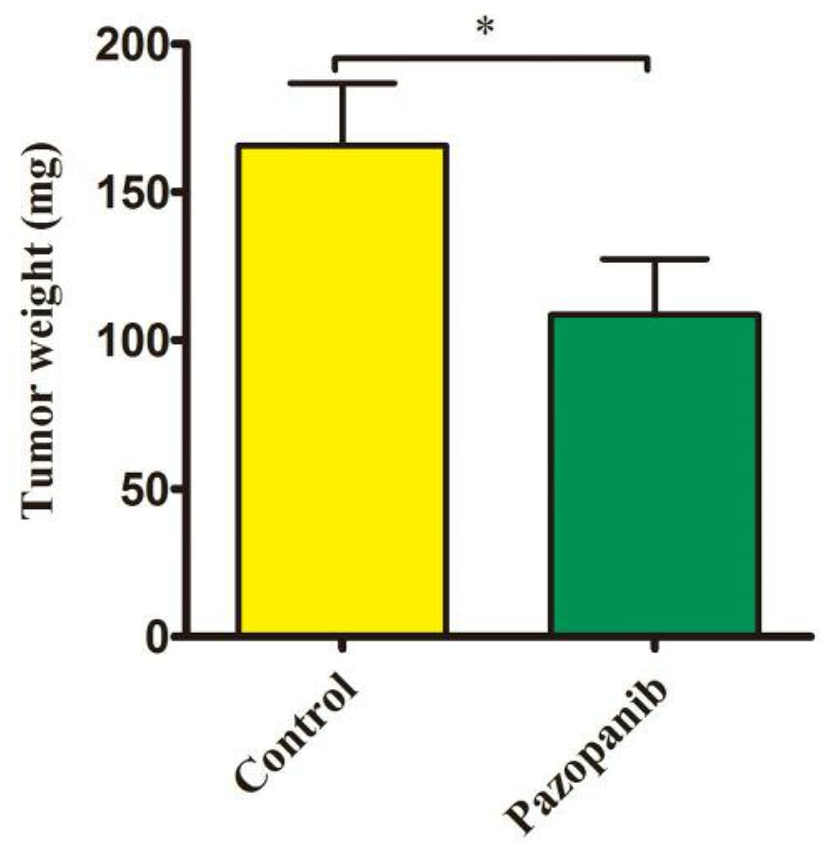

Figure 5. Effect of PAZ on relative tumor volume and tumor weight in the orthotopic CT-26-GFP colorectal cancer nude mouse model at autopsy. (A) Bar graph shows relative tumor volume (tumor volume/100) in the control and PAZ group. (B) Bar graph shows tumor weight in the control and PAZ group. ( $n=5$ in each group, $\left.* p<0.05,{ }^{* *} p<0.01\right)$.

PAZ inhibited the volume and weight of the orthotopic CT26GFP colorectal cancer. The relative tumor volume in the control group was significantly larger compared to the PAZ groups $\left(14 \pm 1.72 \mathrm{~mm}^{3}\right.$ vs. $\left.6.21 \pm 0.85 \mathrm{~mm}^{3}, p<0.01\right)$ (Figure $5 \mathrm{~A})$. The tumor weight at autopsy was significantly reduced in the PAZ-treated group. In the control group, the mean tumor weight was $165.6 \pm 21.1 \mathrm{mg}$, while in the PAZ group it was $108.4 \pm 18.8 \mathrm{mg}$ (Figure 5B) $(p<0.05)$.

Tumor histology analysis. Histologically, the control group tumor mainly comprised viable cancer cells (Figure 6A). In the tumor treated with PAZ, the cancer-cell density was lower compared to that of the control (Figure 6B). This suggested that PAZ inhibited the cancer cell proliferation in the orthotopic CT26-GFP colorectal-cancer nude mice. Figure 6C-E show examples where the tumor invaded the colorectal tissue. Figure $6 \mathrm{~F}-\mathrm{H}$ shows examples where the tumor has invaded lymph nodes. H\&E staining highlights the shape of the lymph nodes that were filled with cancer cells and where the internal structures of the lymph node were destroyed (Figure 6F-H).

PAZ down-regulated the lymphatic vessel density (LVD) in the orthotopically transplanted CT26-GFP colorectal cancer. The lymphatic vessels of the orthotopic CT26-GFP tumors were marked by LYVE-1 antibodies using immunohistochemical staining. The lymphatic vessel density (LVD) of CT26-GFP orthotopic tumors in the PAZ group was significantly lower compared to the control group (Figure 7).

\section{Discussion}

We have previously found that PAZ is effective in PDOX models of sarcoma (20-27). Although, there have been studies of PAZ in colorectal cancer, where it has been shown that it inhibits tumor progression (28-30), no studies have been conducted on how PAZ affects lymphatic metastasis of colorectal cancer. In this study, we confirmed that PAZ inhibits the growth of subcutaneous colon cancer in a nude mice model. In the orthotopic model of CT26-GFP colorectal cancer in nude mice, we found that PAZ was able to inhibit tumor growth, lymphatic metastasis and lymphangiogenesis.

PAZ has a high affinity of VEGFR-1/2/3 and can inhibit the signaling pathway induced by VEGFRs to regulate the corresponding physiological functions (13). In summary, we demonstrated that PAZ can inhibit the growth of colorectal cancer of subcutaneous and orthotopically transplanted tumors in nude mouse models. As far as we are aware, this is the first in vivo study demonstrating that PAZ could inhibit lymph node metastasis and lymphangiogenesis of orthotopic tumors in mice with colorectal cancer. The importance of orthotopic models to study colon cancer is emphasized (31-33). 
A

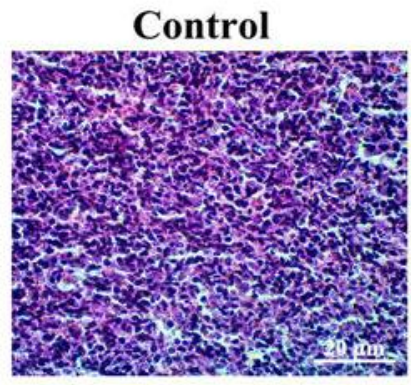

C

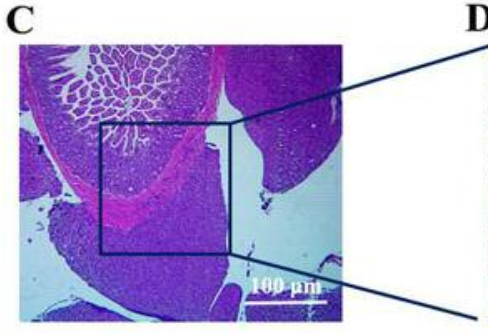

D
B

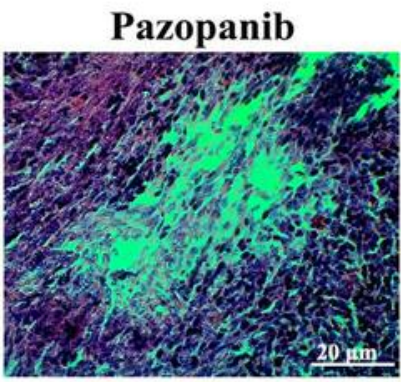

$\mathbf{E}$

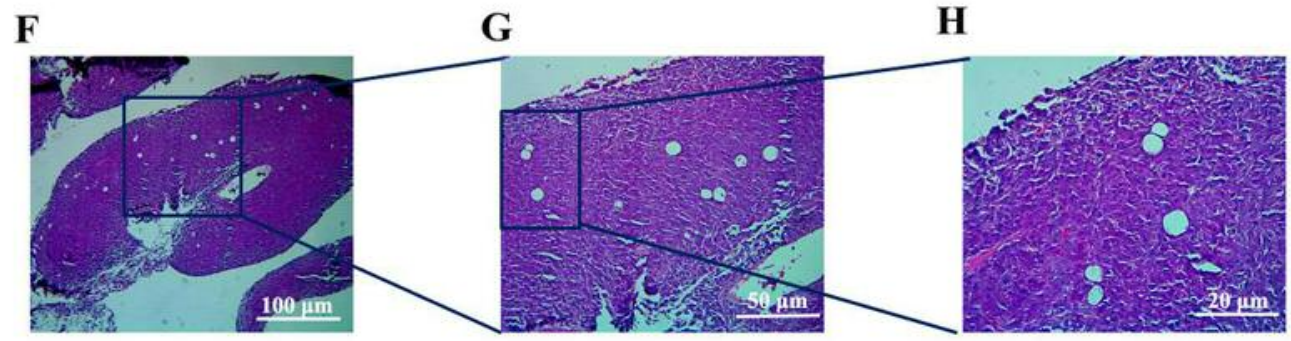

Figure 6. Histology of the CT26-GFP orthotopic colorectal-cancer mouse model. (A) H\&E stained section of the control group. (B) H\&E stained sections of the PAZ group. $(C-E) H \& E$ stained sections of the control tumor invading the intestine. $(F-H) H \& E$ stained sections of metastatic lymph nodes in the control mice. A, B, E, H: Magnification 200x; C, F: magnification, 40x; D, G: magnification, 100x.

A

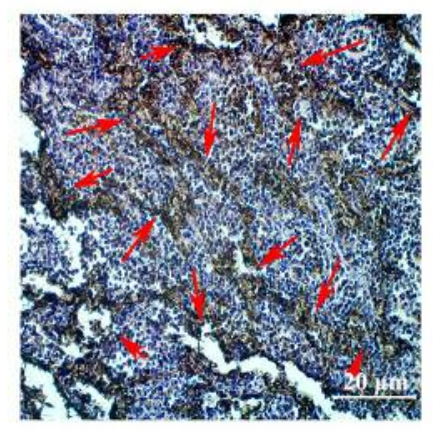

B

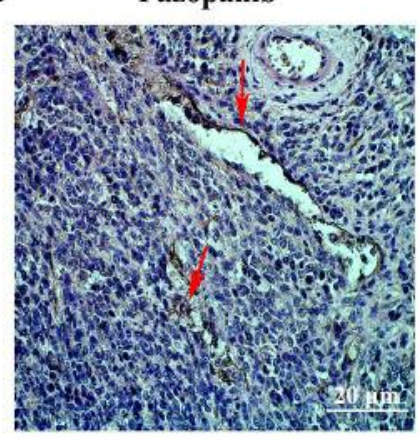

C

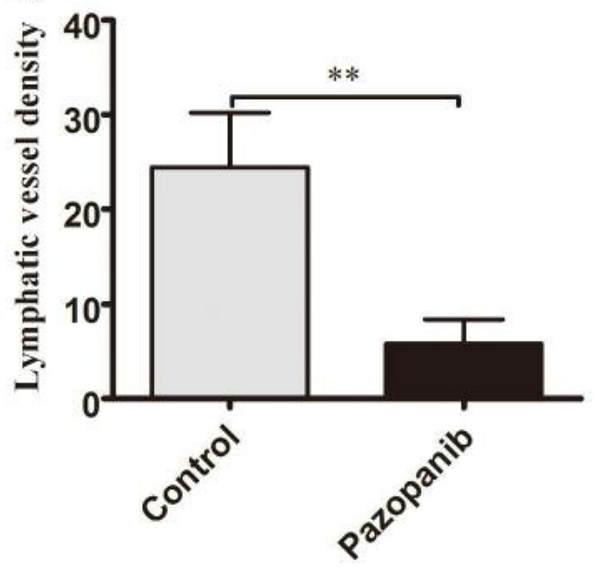

Figure 7. PAZ inhibits lymphangiogenesis of the CT26-GFP orthotopic-colorectal cancer mouse model. (A) Representative lymphatic vessel endothelial hyaluronic acid receptor 1 (LYVE-1) stained in the control tumor (red arrows) and the PAZ group (B; red arrows). (C) The graph shows the corresponding lymphatic vessel density in the control and PAZ group. Magnification $200 \times ; * * p<0.01$. 


\section{Conflicts of Interest}

GZ, YS and RMH are unpaid affiliates of AntiCancer Inc. MZ, YT and $\mathrm{QH}$ are employees of AntiCancer Inc. AntiCancer Inc uses orthotopic mouse models of cancer for contract research. The authors declare no conflicts of interest regarding this study.

\section{Authors' Contributions}

GZ and JY designed the study and wrote the draft manuscript, GZ performed the experiments, MZ, QH and YS supported the experiments, SRS and RMH revised the manuscript. All Authors approved the final manuscript.

\section{Acknowledgements}

This study was supported by the National Natural Science Foundation of China (No. 81702424 and 81872364), The Joint Funds for the Innovation of Science and Technology, Fujian Province (No. 2017Y9092), The Fujian Provincial Health Department Young and Middle-aged Talents Training Project (No. 2018-ZQN-46), The Project of Science and Technology Research Program in Fujian Province (No. 2016B044), The Fujian Provincial Natural Science Foundation (No. 2018J05127), the National Clinical Key Specialty Construction Project (General Surgery) of China. This paper is dedicated to the memory of A.R. Moossa, MD, Sun Lee, MD, Professor Li Jiaxi, and Masaki Kitajima, MD.

\section{References}

1 Neki K, Eto K, Kosuge M, Ohkuma M, Ito D, Takeda Y, Yatabe $\mathrm{S}$, Sugano $\mathrm{H}$ and Yanaga K: Identification of the risk factors for recurrence of stage iii colorectal cancer. Anticancer Res 39: 5721-5724, 2019. PMID: 31570473. DOI: 10.21873/ anticanres. 13772

2 Pyo JS, Kim JH, Lee SY, Baek TH and Kang DW: Metastatic lymph node ratio (mlnr) is a useful parameter in the prognosis of colorectal cancer; A meta-analysis for the prognostic role of mLNR. Medicina 55(10): E673, 2019. PMID: 31590275. DOI: 10.3390/medicina55100673

3 Jin M and Frankel WL: Lymph node metastasis in colorectal cancer. Surg Oncol Clin N Am 27(2): 401-412, 2018. PMID: 29496097. DOI: 10.1016/j.soc.2017.11.011

4 Sun ZQ, Ma S, Zhou QB, Sun ZQ, Ma S, Zhou QB, Yang SX, Chang Y, Zeng XY, Ren WG, Han FH, Xie X, Zeng FY, Sun XT, Wang GX, Li Z, Zhang ZY, Song JM, Liu JB and Yuan WT: Prognostic value of lymph node metastasis in patients with T1stage colorectal cancer from multiple centers in China. World $\mathrm{J}$ Gastroenterol 23(48): 8582-8590, 2017. PMID: 29358866. DOI: 10.3748/wjg.v23.i48.8582

5 Raica M, Jitariu AA and Cimpean AM: Lymphangiogenesis and anti-lymphangiogenesis in cutaneous melanoma. Anticancer Res 36(9): 4427-4435, 2016. PMID: 27630278. DOI: 10.21873/ anticanres.10986

6 Karkkainen MJ and Petrova TV: Vascular endothelial growth factor receptors in the regulation of angiogenesis and lymphangiogenesis. Oncogene 19(49): 5598-5605, 2000. PMID: 11114740. DOI: 10.1038/sj.onc.1203855
7 Karpanen T, Egeblad M, Karkkainen MJ, Kubo H, YläHerttuala S, Jäättelä M, Alitalo K: Vascular endothelial growth factor $\mathrm{C}$ promotes tumor lymphangiogenesis and intralymphatic tumor growth. Cancer Res 61(5): 1786-1790, 2001. PMID: 11280723.

8 He Y, Kozaki K, Karpanen T, Koshikawa K, Yla-Herttuala S, Takahashi $\mathrm{T}$ and Alitalo $\mathrm{K}$ : Suppression of tumor lymphangiogenesis and lymph node metastasis by blocking vascular endothelial growth factor receptor 3 signaling. J Natl Cancer Inst 94(11): 819-825, 2002. PMID: 12048269. DOI: 10.1093/jnci/94.11.819

9 Coso S, Zeng Y, Opeskin K and Williams ED: Vascular endothelial growth factor receptor-3 directly interacts with phosphatidylinositol 3-kinase to regulate lymphangiogenesis. PLoS One 7(6): e39558, 2012. PMID: 22745786. DOI: 10.1371/ journal.pone.0039558

10 Shibuya M and Claesson-Welsh L: Signal transduction by VEGF receptors in regulation of angiogenesis and lymphangiogenesis. Exp Cell Res 312(5): 549-560, 2006. PMID: 16336962. DOI: 10.1016/j.yexcr.2005.11.012

11 Veikkola T, Jussila L, Makinen T, Karpanen T, Jeltsch M, Petrova TV, Kubo H, Thurston G, McDonald DM, Achen MG, Stacker SA and Alitalo K: Signalling via vascular endothelial growth factor receptor-3 is sufficient for lymphangiogenesis in transgenic mice. EMBO J 20(6): 1223-1231, 2001. PMID: 11250889. DOI: $10.1093 / \mathrm{emboj} / 20.6 .1223$

12 Tacconi C, Correale C, Gandelli A, Spinelli A, Dejana E, D'Alessio S and Danese S: Vascular endothelial growth factor C disrupts the endothelial lymphatic barrier to promote colorectal cancer invasion. Gastroenterology 148(7): 1438-1451, 2015. PMID: 25754161. DOI: 10.1053/j.gastro.2015.03.005

13 Schutz FA, Choueiri TK and Sternberg CN: Pazopanib: Clinical development of a potent anti-angiogenic drug. Crit Rev Oncol Hematol 77: 163-171, 2011. PMID: 20456972. DOI: 10.1016/ j.critrevonc.2010.02.012

14 Kumar R, Knick VB, Rudolph SK, Johnson JH, Crosby RM, Crouthamel MC, Hopper TM, Miller CG, Harrington LE, Onori JA, Mullin RJ, Gilmer TM, Truesdale AT, Epperly AH, Boloor A, Stafford JA, Luttrell DK and Cheung M: Pharmacokineticpharmacodynamic correlation from mouse to human with pazopanib, a multikinase angiogenesis inhibitor with potent antitumor and antiangiogenic activity. Mol Cancer Ther 6: 20122021, 2007. PMID: 17620431. DOI: 10.1158/1535-7163.MCT07-0193

15 Kawaguchi K, Igarashi K, Murakami T, Kiyuna T, Nelson SD, Dry SM, Li Y, Russell TA, Singh AS, Chmielowski B, Unno M, Eilber FC and Hoffman RM: Combination of gemcitabine and docetaxel regresses both gastric leiomyosarcoma proliferation and invasion in an imageable patient-derived orthotopic xenograft (iPDOX) model. Cell Cycle 16: 1063-1069, 2017. PMID: 28426279. DOI: 10.1080/15384101.2017.1314406

16 Igarashi K, Kawaguchi K, Kiyuna T, Miyake K, Miyake M, Li Y, Nelson SD, Dry SM, Singh AS, Elliott IA, Russell TA, Eckardt MA, Yamamoto N, Hayashi K, Kimura H, Miwa S, Tsuchiya H, Eilber FC and Hoffman RM: Temozolomide regresses a doxorubicin-resistant undifferentiated spindle-cell sarcoma patient-derived orthotopic xenograft (PDOX): precision-oncology nude-mouse model matching the patient with effective therapy. J Cell Biochem 119: 6598-6603, 2018. PMID: 29737543. DOI: $10.1002 /$ jcb. 26792 
17 Igarashi K, Kawaguchi K, Kiyuna T, Miyake K, Miyake M, Singh AS, Eckardt MA, Nelson SD, Russell TA, Dry SM, Li Y, Yamamoto N, Hayashi K, Kimura H, Miwa S, Tsuchiya H, Singh SR, Eilber FC and Hoffman RM: Tumor-targeting Salmonella typhimurium A1-R is a highly effective general therapeutic for undifferentiated soft tissue sarcoma patientderived orthotopic xenograft nude-mouse models. Biochem Biophys Res Commun 497: 1055-1061, 2018. PMID: 29481803. DOI: $10.1016 /$ j.bbrc.2018.02.174

18 Fu XY, Besterman JM, Monosov A and Hoffman RM: Models of human metastatic colon cancer in nude mice orthotopically constructed by using histologically intact patient specimens. Proc Natl Acad Sci USA 88: 9345-9349, 1991. PMID: 1924398. DOI: $10.1073 /$ pnas.88.20.9345

19 Oshiro H, Kiyuna T, Tome Y, Miyake K, Kawaguchi K, Higuchi T, Miyake M, Zhang Z, Razmjooei S, Barangi M, Wangsiricharoen S, Nelson SD, Li Y, Bouvet M, Singh SR, Kanaya $\mathrm{F}$ and Hoffman RM: Detection of metastasis in a patient-derived orthotopic xenograft (PDOX) model of undifferentiated pleomorphic sarcoma with red fluorescent protein. Anticancer Res 39: 81-85, 2019. PMID: 30591443. DOI: 10.21873/anticanres.13082

20 Igarashi K, Kawaguchi K, Murakami T, Kiyuna T, Miyake K, Singh AS, Nelson SD, Dry SM, Li Y, Yamamoto N, Hayashi K, Kimura H, Miwa S, Tsuchiya H, Eilber FC and Hoffman RM: High efficacy of pazopanib on an undifferentiated spindle-cell sarcoma resistant to first-line therapy is identified with a patient-derived orthotopic xenograft (PDOX) nude mouse model. J Cell Biochem 118: 27392743, 2017. PMID: 28176365. DOI: 10.1002/jcb.25923

21 Hiroshima Y, Zhao M, Zhang Y, Zhang N, Maawy A, Murakami T, Mii S, Uehara F, Yamamoto M, Miwa S, Yano S, Momiyama M, Mori R, Matsuyama R, Chishima T, Tanaka K, Ichikawa Y, Bouvet M, Endo I and Hoffman RM: Tumor-targeting Salmonella typhimurium A1-R arrests a chemo-resistant patient soft-tissue sarcoma in nude mice. PLoS One 10(8): e0134324, 2015. PMID: 26237416. DOI:10.1371/journal.pone.0134324

22 Igarashi K, Kawaguchi K, Kiyuna T, Miyake K, Miyake M, Nelson SD, Russell TA, Dry SM, Li Y, Yamamoto N, Hayashi K, Kimura H, Miwa S, Higuchi T, Singh SR, Tsuchiya H and Hoffman RM: Pazopanib regresses a doxorubicin-resistant synovial sarcoma in a patient-derived orthotopic xenograft mouse model. Tissue Cell 58: 107-111, 2019. PMID: 31133237. DOI: $10.1016 /$ j.tice.2019.04.010

23 Kiyuna T, Murakami T, Tome Y, Igarashi K, Kawaguchi K, Miyake K, Miyake M, Li Y, Nelson SD, Dry SM, Singh AS, Russell TA, Singh SR, Kanaya F, Eilber FC and Hoffman RM: Doxorubicin-resistant pleomorphic liposarcoma with PDGFRA gene amplification is targeted and regressed by pazopanib in a patient-derived orthotopic xenograft mouse model. Tissue Cell 53: 30-36, 2018. PMID: 30060824. DOI: 10.1016/j.tice.2018.05.010

24 Kiyuna T, Tome Y, Murakami T, Miyake K, Igarashi K, Kawaguchi K, Oshiro H, Higuchi T, Miyake M, Sugisawa N, Zhang Z, Razmjooei S, Wangsiricharoen S, Chmielowski B, Nelson SD, Russell TA, Dry SM, Li Y, Eckardt MA, Singh AS, Chawla S, Kanaya F, Eilber FC, Singh SR, Zhao M and Hoffman RM: A combination of irinotecan/cisplatinum and irinotecan/temozolomide or tumor-targeting Salmonella typhimurium A1-R arrest doxorubicin- and temozolomide-resistant myxofibrosarcoma in a PDOX mouse model. Biochem Biophys Res Commun 505: 733739, 2018. PMID: 30292411. DOI: 10.1016/j.bbrc.2018.09.106
25 Miyake K, Higuchi T, Oshiro H, Zhang Z, Sugisawa N, Park JH, Razmjooei S, Katsuya Y, Barangi M, Li Y, Nelson SD, Murakami T, Homma Y, Hiroshima Y, Matsuyama R, Bouvet M, Chawla SP, Singh SR, Endo I and Hoffman RM: The combination of gemcitabine and docetaxel arrests a doxorubicinresistant dedifferentiated liposarcoma in a patient-derived orthotopic xenograft model. Biomed Pharmacother 117: 109093, 2019. PMID: 31200257. DOI: 10.1016/j.biopha.2019.109093

26 Oshiro H, Tome Y, Kiyuna T, Miyake K, Kawaguchi K, Higuchi T, Miyake M, Zang Z, Razmjooei S, Barangi M, Wangsiricharoen S, Nelson SD, Li Y, Bouvet M, Singh SR, Kanaya F and Hoffman RM: Temozolomide targets and arrests a doxorubicin-resistant follicular dendritic-cell sarcoma patientderived orthotopic xenograft mouse model. Tissue Cell 58: 1723, 2019. PMID: 31133242. DOI: 10.1016/j.tice.2019.04.002

27 Zhang Z, Hu K, Kiyuna T, Miyake K, Kawaguchi K, Igarashi K, Nelson SD, Li Y, Singh SR and Hoffman RM: A patient-derived orthotopic xenograft (PDOX) nude-mouse model precisely identifies effective and ineffective therapies for recurrent leiomyosarcoma. Pharmacol Res 142: 169-175, 2019. PMID: 30807865. DOI: $10.1016 /$ j.phrs.2019.02.021

28 Bennouna J, Deslandres M, Senellart H, de Labareyre C, Ruiz-Soto R, Wixon C, Botbyl J, Suttle AB and Delord JP: A phase I openlabel study of the safety, tolerability, and pharmacokinetics of pazopanib in combination with irinotecan and cetuximab for relapsed or refractory metastatic colorectal cancer. Invest New Drugs 33: 138147, 2015. PMID: 25248752. DOI: 10.1007/s10637-014-0142-1

29 Fu S, Hou MM, Naing A, Janku F, Hess K, Zinner R, Subbiah V, Hong D, Wheler J, Piha-Paul S, Tsimberidou A, Karp D, Araujo D, Kee B, Hwu P, Wolff R, Kurzrock R and Meric-Bernstam F: Phase I study of pazopanib and vorinostat: a therapeutic approach for inhibiting mutant p53-mediated angiogenesis and facilitating mutant p53 degradation. Ann Oncol 26: 1012-1018, 2015. PMID: 25669829. DOI: 10.1093/annonc/mdv066

30 Zhang L, Wang H, Li W, Zhong J, Yu R, Huang X, Wang H, Tan Z, Wang $J$ and Zhang Y: Pazopanib, a novel multi-kinase inhibitor, shows potent antitumor activity in colon cancer through PUMA-mediated apoptosis. Oncotarget 8: 3289-3303, 2017. PMID: 27924057. DOI: 10.18632/oncotarget.13753

31 Hiroshima Y, Maawy A, Metildi CA, Zhang Y, Uehara F, Miwa S, Yano S, Sato S, Murakami T, Momiyama M, Chishima T, Tanaka K, Bouvet M, Endo I and Hoffman RM: Successful fluorescence-guided surgery on human colon cancer patientderived orthotopic xenograft mouse models using a fluorophoreconjugated anti-CEA antibody and a portable imaging system. J Laparoendosc Adv Surg Tech A 24(4): 241-247, 2014. PMID: 24494971. DOI: 10.1089/lap.2013.0418

32 Kuo TH, Kubota T, Watanabe M, Furukawa T, Teramoto T, Ishibiki K, Kitajima M, Moossa AR, Penman S and Hoffman RM: Liver colonization competence governs colon cancer metastasis. Proc Natl Acad Sci U S A 92(26): 12085-12089, 1995. PMID: 8618849. DOI: 10.1073/pnas.92.26.12085

33 Hoffman RM: Orthotopic is orthodox: Why are orthotopictransplant metastatic models different from all other models? J Cell Biochem 56(1): 1-3, 1994. PMID: 7806583. DOI: $10.1002 /$ jcb. 240560102

Received November 12, 2019

Revised November 27, 2019

Accepted December 3, 2019 